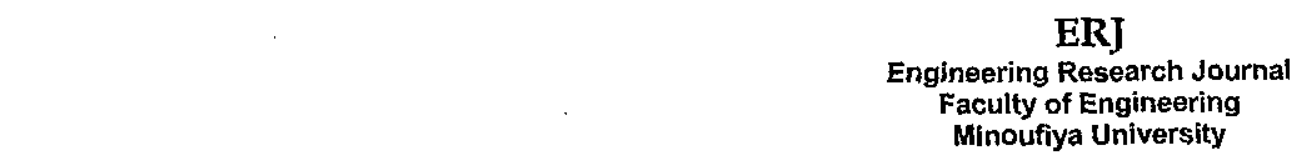

\title{
MODE II FRUCTURE TOUGHNESS OF HYBRID FIBER REINFORCED CONCRETE
}

\author{
A. M. Saba \\ Materials Engineering Department, Zagazig University, Zagazig, EGYPT
}

\begin{abstract}
Mode II fracture toughness of hybrid fiber reinforced concrete HFRC has been experimentally investigated. The effect of crack length to depth ratio, aiw, was studied. The mechanical properties of different hybrid fiber reinforced concretes were determined in an attempt to relate the parameters of concrete type to its fracture toughness. Three different fiber types (steel "S", glass "G" and polypropylene "Pp") were used. The volume fraction $V_{f}$ was kept constant equal to $1.5 \%$ for all FRCs with different configurations. These configurations are steel fiber only with $1.5 \% V_{f}$ (SFRC), steel fiber with $1 \% \mathrm{~V}_{\mathrm{f}}$ in addition to glass fiber with $0.5 \% \mathrm{~V}_{\mathrm{f}}$ (SGFRC), and steel fiber with $1 \% \mathrm{~V}_{f}$ in addition to polypropylene fiber with $0.5 \% \mathrm{~V}_{\mathrm{f}}(\mathrm{SPPFRC})$. The crack length to depth ratio was equal to $0.3,0.4$ and 0.5 for fracture toughness specimens. The cement content was 450 $\mathrm{kg} / \mathrm{m}^{3}$ for all mixes. The fracture toughness $\mathrm{K}_{\mathrm{irC}}$ was determined according to formula of Watkins model by using cracked cubes 150 X $150 \times 150 \mathrm{~mm}$. Results of the present work indicated that, the addition of short fibers slightly increase the compressive strength of FRC. The presence of fibers significantly increases the splitting tensile strength of FRC for different types of fibers. For Plain concrete $K_{\text {IIC }}$ was not dependent on the value of $a / w$, i.e. intrinsic property. On the other hand, The mode II fracture toughness ( $\mathrm{K}_{\text {IIC }}$ ) for all FRCs mixes, decreases with the increase in the ratio $a / w$ due to the absence of fibers to connect the two surfaces of pre-crack.

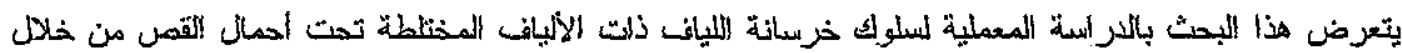

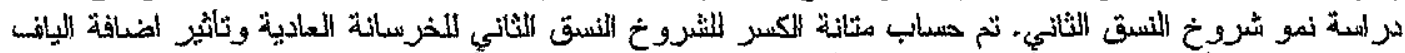

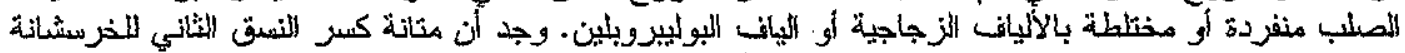

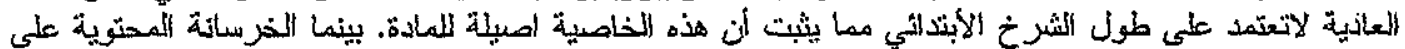

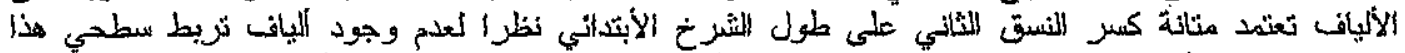

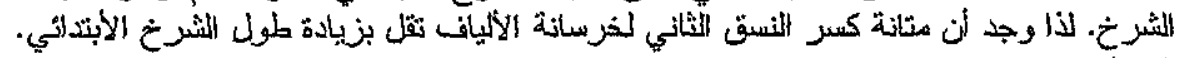

Keywords: Mode II, Fracture toughness, Hybrid Fiber Reinforced Concrete; Steel fibers; Glass fibers; polypropylene fibers.

\section{INTRODUCTION}

Concrete is a quasi-brittle material with a low strain capacity. Reinforcement of concrete with short randomly distributed fibers can address some of the concerns related to concrete brittleness and poor resistance to crack growth. Fibers, used as reinforcement, can be effective in arresting cracks at both micro- and macro-levels. At the micro-level, fibers inhibit the initiation and growth of cracks, and after the micro-cracks coalesce into macro-cracks, fibers provide mechanisms that abate their unstable propagation, provide effective bridging, and impart sources of strength gain, toughness and ductility [1, 2]. Almost all FRCs used today commercially involve the use of a single fiber type. Clearly, a given type of fiber can only be effective in a limited range of crack opening and deflection. The benefits of combining different fibers types to achieve superior tensile strength and fracture toughness were recognized nearly 30 years ago by Walton and Majumdar [3]. After a long period of relative inactivity, there appears to be a renewed interest in hybrid fiber composites and efforts are underway to develop the science and rationale behind fiber hybridization. In well-designed hybrid composites, there is a positive interaction between the fibers and the resulting hybrid performances that exceeds the sum of individual fiber performances. This phenomenon is often termed "Synergy". Many fiber combinations may provide 'Synergy' with the most commonly recognized being [4,5]: Hybrids based on fiber constitutive response, where one type of fiber is stronger and stiffer provjding reasonable first crack strength and ultimate strength, while the second type of fiber is relatively flexible leading to improved toughness and strain capacity in the post-crack zone. The second type is hybrids based on fiber dimensions, where one type of fiber is smaller so that it bridges micro-cracks and therefore controls their growth and delays coalescence leading to a higher tensile strength of the composite, while the second fiber is larger and is intended to arrest the propagation of macro-cracks and therefore resulting in a substantial improvement in the fracture 
toughness of the composite. Recently Banthia and Soleimani [6] summarized most of published research on HFRC and they concluded that, "in spite of these efforts, clearly, our understanding of what exactly constitutes an optimal combination of fibers capable of producing maximum synergy in performance remains quite limited".

Fracture mechanics terminology. defines three different cracking modes: (i) mode-I - opening mode, (ii) mode-II - shearing mode and (iii) mode-III - tearing mode. At the macro-scale these modes describe three independent kinematics movements of the upper and lower crack surface with respect to each other and are sufficient to define all possible modes of crack propagation in an elastic material. In practice most cracks in concrete and reinforced concrete structures result from mode-I fracture, or from the combination of mode-I and other modes. A frequently observed combination of modes is the combination of mode-I and mode-II, the so-called mixed-mode fracture. Typical examples are diagonal shear failure of reinforced concrete beams or punching of flat slabs. In the past an enormous amount of experimental and theoretical work has been done to understand mode-I fracture, however, relatively few studies have investigated mixed-mode fracture of concrete. For this reason, nonlinear mode II and mixed-mode theories are not yet well developed for concrete-like materials $[7,8]$. In order to investigate mode II crack propagation and to collect mode II fracture toughness, $\mathrm{K}_{\text {IIC, }}$ it is important to find a suitable testing method of mode II fracture, see for example Refs. 7 and 8 . In this work, the effect of crack depth ratio, fibre type and hybrids response on the $\mathrm{K}_{\text {IIC }}$ were experimentally investigated for the FRC.

\section{EXPERIMENTAL WORK}

In this paper an attempt is made to establish the influence of hybrid fiber on mode II fracture toughness of plain concrete. The experimental program included four group, one of plain concrete (PC) and three group of fiber reinforced concrete (SFRC, SGFRC, SPPFRC). Each group contain, cube, cylinder and double notched cube specimens. Three specimens per sample were used for each tested parameter.

The cement used in all concrete mixes was ordinary Portland cement. The sand used was local natural siliceous sand with specific gravity of 2.55 and fineness modulus of 2.61. The coarse aggregate was dolomite with nominal maximum size of $14 \mathrm{~mm}$ and specific gravity of 2.6. A superplasticizer called Adecrite PVF (naphthalene sulphonated compound) was chosen. Galvanized steel fiber used in this work was crumpled around each other to form a filament twin fiber. This shape of fiber achieves a good bond between the matrix and the fiber due to the development of the mechanical bond depending on the fiber geometry. The fiber length was $25 \mathrm{~mm}$ and the plain fiber cross sectional diameter was $0.5 \mathrm{~mm}$ so the aspect ratio was 50 , and the modulus of elasticity was $200 \mathrm{GPa}$. Alkaline resistance glass fiber (NEG ARG fiber) was used in this work and it achieves its high alkali resistance from the high zirconia's content in its glass composition. The fiber supplied in chopped strands of $25 \mathrm{~mm}$ length. The modulus of elasticity and the ultimate tensile strength of the used glass fiber were $74 \mathrm{GPa}$ and $1400 \mathrm{MPa}$ respectively. For polypropylene fiber, the used type called MC-Fiber, it was $15 \mathrm{~mm}$ length and 0.0965 $\mathrm{mm} \pm 10 \%$ thickness, the modulus of elasticity and the ultimate tensile strength were $3.7 \mathrm{GPa}$ and $600 \mathrm{MPa}$ respectively. In addition to $\mathrm{PC}$ three different types of fiber were used, i.e. steel, glass, and poly propylene. The volume fraction (Vf) was kept constant equal to $1.5 \%$ for all mixes of fiber reinforced concrete (FRC) with three configurations: (1) Vf $=1.5 \%$ steel fiber abbreviated as SFRC specimens, (2) Vf $=1 \%$ steel fiber and $0.5 \%$ glass fiber abbreviated as GFRC specimens, and (3) $\mathrm{Vf}=$ $1 \%$ steel fiber and $0.5 \%$ polypropylene fiber abbreviated as SPPFRC specimens. Cubes $150 \times 150$ $\mathrm{x} 150 \mathrm{~mm}$ were prepared to be tested under static compression. On the other hand, double notched cubes with the same dimensions and notch to depth ratios, $a / w$, of $(0.3,0.4$, and 0.5$)$ were cast to evaluate the fracture toughness. The notch of the specimen was created using a steel plate of $0.5 \mathrm{~mm}$ thickness and apex angle $30^{\circ}$.Cylinders of $100 \mathrm{~mm}$ diameter and $200 \mathrm{~mm}$ height were prepared to be tested under indirect tension.

The absolute volume method was used to determine the concrete mix proportions. Table 1 presents these proportions. A vertical mixer of revolving blades type was used in mixing. Materials of the specified mix were weighed first and then mixed in a dry state for about 2 minutes. The required amount of water and superplasticizer was then added in pushes during the next two minutes. The contents were left to agitate in the mixer until a homogenous mix was obtained. The fiber was then added in small increments by sprinkling them onto the surface of the mix until all the fibers were absorbed into the matrix. The freshly mixed concrete was tested for slump as a quality control test, the result was about $(80 \mathrm{~mm})$ for $\mathrm{PC}$ mixes whereas about $(50 \mathrm{~mm})$ for the fiber mixed materials. The mixed materials were then placed in the molds, compacted using external vibration, leveled, and cured in water for 28 days before testing.

The tests of mode II fracture toughness was carried out on the stand presented in Fig. (1). 
Table 1: Mix Proportions by Weight

\begin{tabular}{|c|c|c|c|c|}
\hline Cement & Sand & Dolomite & Water & Superplasticizer \\
\hline $450 \mathrm{Kg} / \mathrm{m}^{3}$ & $650 \mathrm{Kg} / \mathrm{m}^{3}$ & $1047 \mathrm{Kg} / \mathrm{m}^{3}$ & $202.5 \mathrm{Lit} / \mathrm{m}^{3}$ & $4.5 \mathrm{Kg} / \mathrm{m}^{3}$ \\
\hline 1 & 1.44 & 2.33 & 0.45 & 0.01 \\
\hline
\end{tabular}
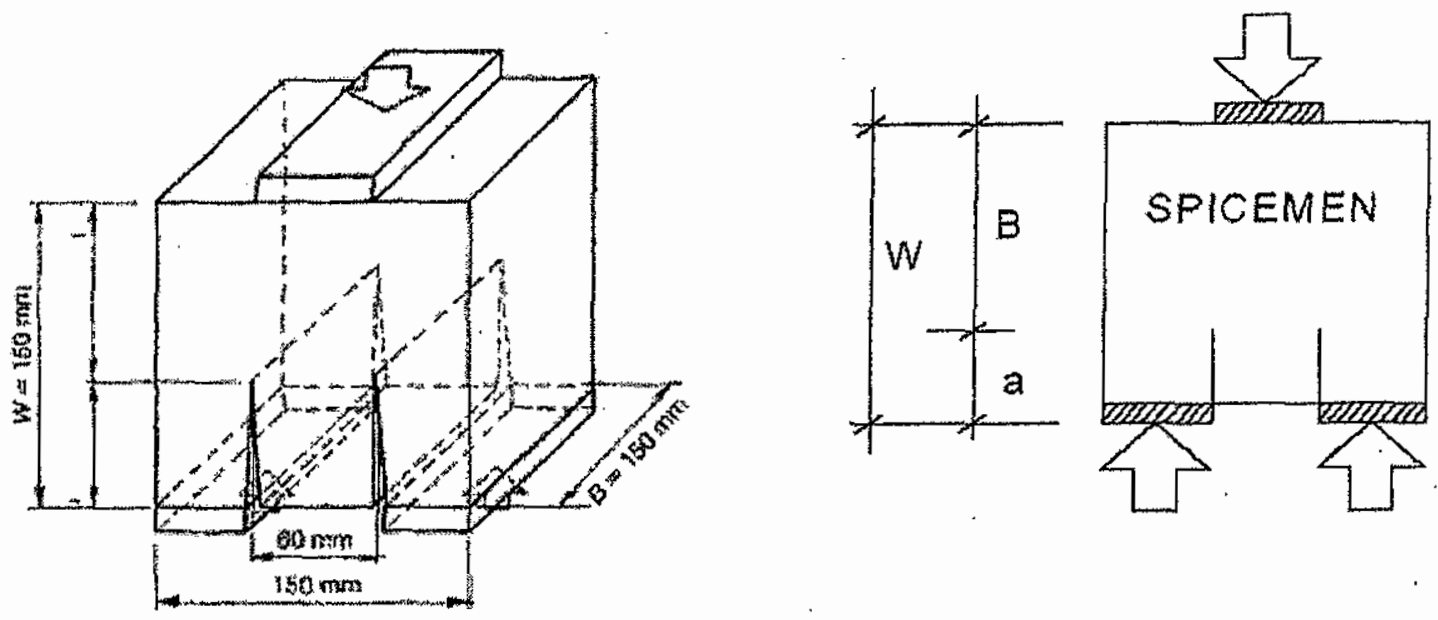

Fig. 1 Scheme of test stand.

The stress intensity factor $\mathrm{K}_{\text {IIC }}$ was determined according to a formula of Watkins as mentioned in Ref. 8:

Where:

$$
\mathbf{K}_{\mathrm{IIC}}=\frac{5.11 P_{Q}}{2 \Omega W} \sqrt{\pi a}
$$

$\mathrm{P}_{\mathrm{Q}}$ is the force initiating cracking (growth),

$B$ is the thickness under the crack;

$W$ is the height and (a) is the length of the crack.

The experimental program was conducted in two groups to investigate the behavior of steel connections in the absence or presence of cracks or holes. All specimens were tested under axial tensile stress. The load elongation curve, ultimate loads and modes of failure of the tested connections were recorded.

\section{RESULTS AND DISCUSSION}

Table (2) shows the experimental results of the ultimate compressive and tensile strengths of the PC and FRC test specimens. The percentage values relative to $P C$ values are given also in Table (2). In general, the results of the present work indicated that the compressive and tensile strengths of FRC test specimens showed a slight improvement when compared with the PC strength. SFRC mix showed a good improvement in the mean value of compressive strength. Compressive strength values, relatively, increase when compared to the PC mix. This can be related to its good mechanical bond due to the filament twin fiber geometry. Crumbled steel fibers showed the most efficient crack retardation due to their" geometry, which improved the bond between them and cement paste. Furthermore, SPPFRC mix showed higher compressive strength values, when compared to the other mixes. For all FRCs mixes a reasonable development in splitting tensile strength was observed due to the presence of fiber. In general, the effect of fiber in FRCs to improve the tensile strength may be due to the random orientation of the fibers.

For SFRC mix showed a good improvement in the splitting tensile strength. It showed an average of about, $71 \%$ increase in the splitting tensile strength, when compared to the PC mix. This can be related to its good mechanical bond due to the filament twin fiber geometry and for arrester of crack by fiber. SPPFRC mix, generally, showed higher splitting tensile strength values, when compared to the the plain concrete mixes FRC. It showed an average of about, $74 \%$ increase in the splitting tensile strength strength, when compared to the PC mix. However, the resuits for SGFRC showed average splitting tensile strength gain values of about $42 \%$ when compared to the PC mix. The failure occurred for all FRC test specimens successively, i.e. no sudden failure occurred in indirect tensile test.

Table 3 show the test results of specimens for mode II fracture toughness, $\mathrm{K}_{\text {IIC. }}$. The table contains the average of the ratio between the cracked and ultimate 


\section{A. M. Saba, "Mode II Fructure Toughness of Hybrid Fiber Reinforced Concrete"}

load for each specimen. The stress intensity factor $\mathrm{K}_{\mathrm{IIC}}$ was determined and shown in Table 3 . Figure 2 shows the relation between the fracture toughness $\mathrm{K}_{\mathrm{IIC}}$ and the crack length to depth ratio a/w for $\mathrm{PC}$ and FRCs. It can be noticed that, the magnitude of $K_{\text {IIC }}$ not changed with increase of the value of $(a / w)$ for $\mathrm{PC}$. This means that, $\mathrm{K}_{\mathrm{IIC}}$ is an intrinsic property of PC. For all FRCs, the $\mathrm{K}_{\mathrm{IIC}}$ decreases with the increase in the ratio $a / w$ due top the absence of connected fiber on the the two surfaces of pre-crack.
These results were also attributed to the weakness of the stiffness of fiber against shear deformation resulting from driving force in mode II. Furthermore, the increase in $a / w$ causes a high localized intensive strain zone ahead the crack. This intensive strain can not totally resisted by a random short fiber. Moreover, one can notice that the rate of decreasing in $\mathrm{K}_{\mathrm{nC}}$ for SGFRC is less than that in case of SFRC. Photo 1 shows the mode II crack growth.

Table (2) The compressive and tensile strength of PC concrete and FRCs in MPa.

\begin{tabular}{|c|c|c|c|c|c|c|}
\hline \multirow{2}{*}{ Mix } & Fiber Type & $\begin{array}{c}\text { Fiber Content } \\
\mathbf{V}_{\mathrm{f}} \%\end{array}$ & \multicolumn{2}{|c|}{ Compressive, $f_{c}$} & \multicolumn{2}{|c|}{ Tensile, $f_{t}$} \\
\cline { 5 - 8 } & & & $f_{c} \mathrm{MPa}$ & $\%$ & $f_{i} \mathrm{MPa}$ & $\%$ \\
\hline PC & $\begin{array}{c}\text { Plain concrete } \\
\text { (PC) }\end{array}$ & $-\cdots$ & 38.5 & 100 & 3.1 & 100 \\
\hline SFRC & Steel (S) & 1.5 & 41.6 & 108 & 5.3 & 171 \\
\hline SGFRC & Steel(S) +Glass (G) & $1.0 \mathrm{~S}+0.5 \mathrm{G}$ & 40.7 & 106 & 4.4 & 142 \\
\hline SPPFRC & Steel (S)+ PP & $1.0 \mathrm{~S}+0.5 \mathrm{PP}$ & 42.6 & 110.6 & 5.4 & 174 \\
\hline
\end{tabular}

Table (3): The test results of PC and FRC test specimens

\begin{tabular}{|c|c|c|c|c|c|c|}
\hline \multicolumn{2}{|r|}{ Mix } & \multirow{2}{*}{ specimen } & \multirow{2}{*}{$a / w$} & \multicolumn{2}{|c|}{ Load $k \mathbf{~}$} & \multirow{2}{*}{ Average Pcr/Pult } \\
\hline symbol & Fiber Type & & & Pcrack & Pult. & \\
\hline \multirow{3}{*}{$\mathrm{PC}$} & \multirow{3}{*}{ Ordinary concrete } & $\mathrm{PC} \mathrm{C1}$ & 0.3 & $66.5,70,74.5$ & $145,190,88$ & 0.56 \\
\hline & & $\mathrm{PC} \mathrm{C} 2$ & 0.4 & $60,62,58$ & $94,150,100$ & 0.54 \\
\hline & & $\mathrm{PC} \mathrm{C3}$ & 0.5 & $49,49.5,58.5$ & $94,93,102$ & 0.54 \\
\hline \multirow{3}{*}{ SFRC } & \multirow{3}{*}{ Steel fiber $1.5 \%$ vf. } & $\mathrm{S} \mathrm{Cl}$ & 0.3 & $102,110,105$ & $223,310,201$ & 0.44 \\
\hline & & $\mathrm{S} \mathrm{C} 2$ & 0.4 & $70,85,79$ & $132,158,145$ & 0.54 \\
\hline & & $\mathrm{S} \mathrm{C} 3$ & 0.5 & $65,62,58$ & $100,110,110$ & 0.58 \\
\hline \multirow{3}{*}{ SGFRC } & \multirow{3}{*}{$\begin{array}{c}1.0 \% \text { steel } \\
+0.5 \% \text { glass vf. }\end{array}$} & SG C1 & 0.3 & $98, \quad 87, \quad 61$ & $178,140,88$ & 0.62 \\
\hline & & SG C2 & 0.4 & $65,70,72$ & $167,143,153$ & $0.4 \dot{5}$ \\
\hline & & $\mathrm{SG} C 3$ & 0.5 & $62,60,55$ & $130,140,117$ & 0.46 \\
\hline \multirow{3}{*}{ SPPFRC } & \multirow{3}{*}{$\begin{aligned} & 1.0 \% \text { steel } \\
+ & 0.5 \% \text { pp vf. }\end{aligned}$} & SPP C1 & 0.3 & $91,72,111$ & $218,218,183$ & 0.45 \\
\hline & & SPP C2 & 0.4 & $70,68, \quad 74$ & $171,176,166$ & 0.39 \\
\hline & & SPP C3 & 0.5 & $54,55,60$ & $113,121,135$ & 0.46 \\
\hline
\end{tabular}




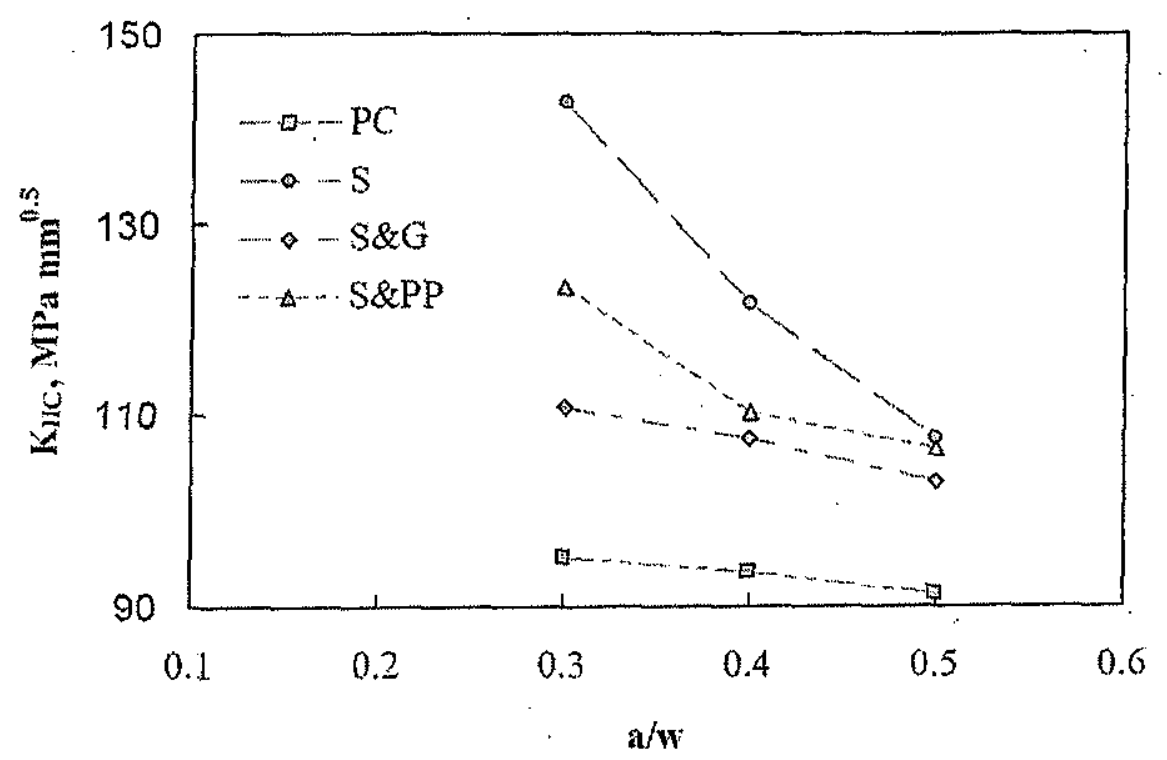

Fig. (2): The fracture toughness $K_{\text {IIc }}$ for PC and different FRC.

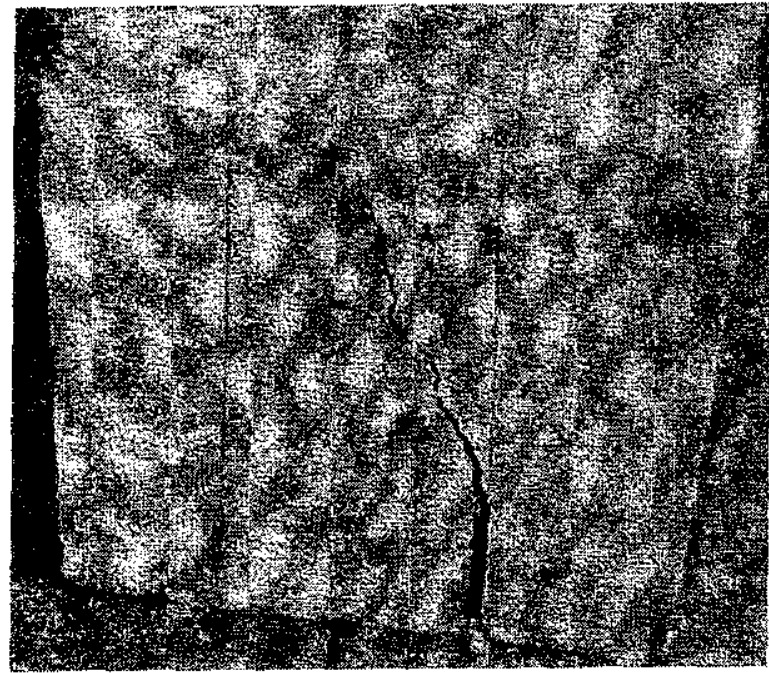

Photo 1: Mode II crack growth in FRC.

\section{CONCLUSIONS}

From the experimental results obtained in this study, the following conclusions can be drawn:

1. All FRCs showed good improvement in the compressive strength when compared to the plain concrete.

2. The SPPFRC showed an improvement in the compressive strength compared to $\mathrm{PC}$ and others FRCs.

3. For all FRCs mixes a reasonable development in splitting tensile strength was observed due to the presence of fiber.

4. For PC mix, the magnitude of $K_{\mathrm{rrC}}$ not changed with increase of the value of $(a / w)$.

5. The Fracture toughness $\mathrm{K}_{\text {IIC }}$ for all FRCs mixes, decreases with the increase in the ratio $a / w$.

\section{REFERENCES}

[1] Bentur, A. and Mindess, S., Fiber Reinforced Cementitious Composites, Elsevier Applied Science, London, 1990.

[2] Balaguru P. N., and Shah S. P., Fiber Reinforced Cement Composites, McGraw-Hill, Inc., New York, 1992.

[3] Walton, P. L. and Majumdar, A. J., "Cementbased composites with mixtures of different types of fiber", Composites, Vol. 15, pp. 209-216, 1975.

[4] Xu, G., Magnani, S., and . Hannant, D. J., Durability of hybrid polypropylene-glass fiber cement corrugated sheets, Cement and Concrete Composites Vol.20, pp. 79-84, 1998.

[5] Aydin, A. C., Self compactability of high volume hybrid fiber reinforced concrete, Construction and Building Materials, Vol. 21, pp. 1149-1154, 2007.

[6] Banthia, N. and Soleimani, S. M., Flexural response of hybrid fiber-reinforced cementitious composites, ACI Materials Journal, Vol. 102, pp. 382-389, 2005.

[7] OŽBOLT, J. and REINHARDT, H.W., Numerical study of mixed-mode fracture in concrete, International Journal of Fracture, Vol. 118, pp. 145-161, 2002.

[8] Prokopski, G. "Effect of coarse aggregate quantity on fracture toughness of Concretes", Journal of Material Science, Vol. 28, pp. 5.717$5721,1993$. 